Research Article

\title{
Pore Water Pressure Responses in Sand Stratum during Shield Tunnelling: A Case Study
}

\author{
Yu Liang $\mathbb{D}^{1},{ }^{1}$ Yufei Xiao $\mathbb{D D}^{2},{ }^{2}$ and Yuexiang Lin ${ }^{1}{ }^{1}$ \\ ${ }^{1}$ School of Aeronautics and Astronautics, Sun Yat-Sen University, Shenzhen 518000, China \\ ${ }^{2}$ Sinohydro Bureau 8 Co., Ltd., Changsha 410000, China \\ Correspondence should be addressed to Yuexiang Lin; linyx86@mail.sysu.edu.cn
}

Received 14 December 2019; Revised 3 September 2020; Accepted 18 September 2020; Published 15 October 2020

Academic Editor: Valeria Vignali

Copyright (c) $2020 \mathrm{Yu}$ Liang et al. This is an open access article distributed under the Creative Commons Attribution License, which permits unrestricted use, distribution, and reproduction in any medium, provided the original work is properly cited.

When shield tunnelling is in a water-rich sand stratum with poor bearing capacity, instability is easily generated, and even ground collapses may occur. The variation of pore water pressure in a water-rich sand stratum during shield tunnelling was analyzed based on a large-scale cross-river shield tunnel in China, which was also investigated by a three-dimensional fluid-solid coupling finite element model. The results show that the influence range of the pore water pressure in front of the excavation face is approximately 2.0 times the excavation diameter and 1.5 times on both sides of the shield. The tunnelling steps would cause obvious variation in the pore water pressure and lead to great disturbance to the surrounding fine sand stratum. The quality of filter cake and the set of support pressure imposes an important impact on the nonlinear variation in the pore pressure, which could cause great disturbance to the stratum. To ensure the safety of the subsequent tunnelling in the fine sand layer, effective treatment should be taken.

\section{Introduction}

With the rapid urban development, how to quickly cross the river and to link the two sides of a city have become the main concerns for modern society. The utilization of cross-river shield tunnel obviously is an inevitable choice for its excellent tunnelling speed, lower environmental impact, and safety. For example, the Channel Tunnel (1994), the Tokyo Bay Cross-Sea Tunnel (1997, Japan), the Elbe River Fourth Highway Tunnel (2003, Germany), the "Green Heart" Railway Tunnel (2007, Netherlands), the Port Miami Road Tunnel (2003, USA), the Orlovsky River Road Tunnel (under construction, Russia), and the New Suez Canal Tunnel (under construction, Egypt) are parts of the famous crossriver shield projects with large diameter in the world. Recently, with the development of shield tunnelling technology and the continuous improvement of economic level, China has been launching numerous large-scale shields tunnelling projects cross river or sea [1]. The author had made statistics on the cross-river shield tunnel in China with a diameter of more than $10 \mathrm{~m}$, which had been built or under construction up to August 2019, as shown in Figure 1. The number of shield cross-river tunnels in China has increased dramatically. At present, at least 48 large-diameter shield tunnels with a diameter of more than $10 \mathrm{~m}$ have been built (27) or under construction (21), among which there are more than 30 large-diameter shield tunnels with a diameter of more than $14 \mathrm{~m}$.

During construction of a cross-river shield tunnel, the covered soil in the flood plain along the river is usually shallow, and water-rich sand strata usually appear. Compared with clay strata [2], the mechanical properties of sand strata are more complex and of poor stability [3]. This may cause instability on the excavation surface and even ground collapse during shield tunnelling $[4,5]$. When shield tunnelling in water-rich sand strata, the variation in the pore water pressure in the soil will influence the state of the soil stress and change the physical and mechanical properties of the soil. Furthermore, the soil permeability will also be impacted by this variation, thus affecting the seepage state and further influencing the stability of the tunnel excavation face [6]. Therefore, it is necessary to analyze the pore water 


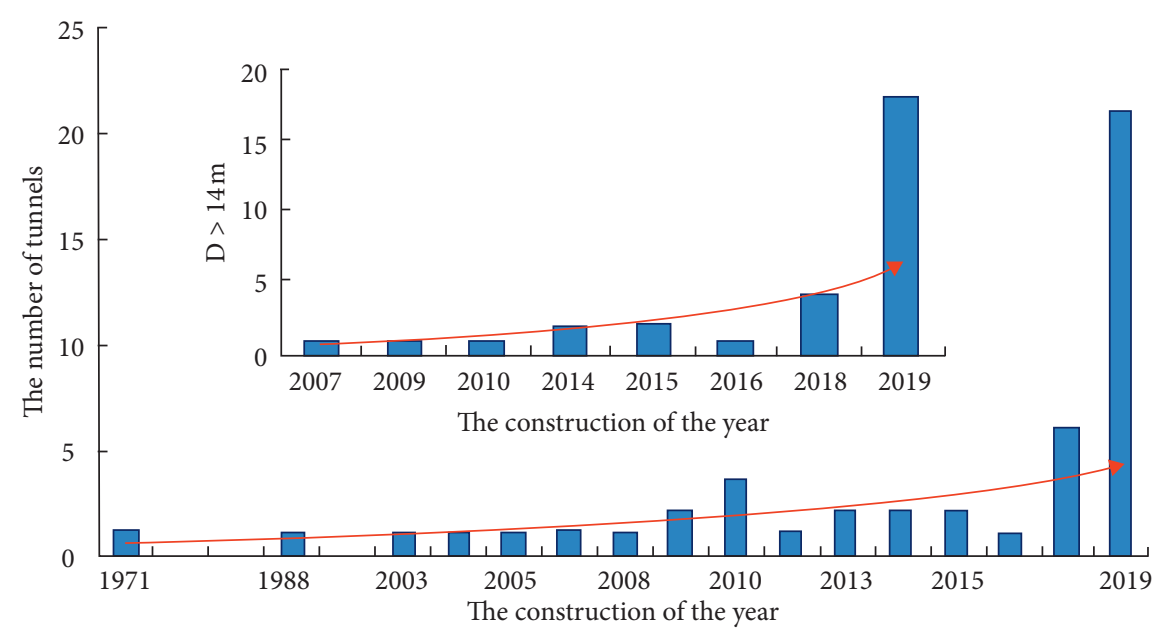

Figure 1: Construction of cross-river shield tunnels in China.

pressure responses during shield tunnelling in the highly permeable sand stratum.

Currently, research on the pore water pressure responses caused by shield tunnelling mainly includes field monitoring, theoretical analysis, and numerical simulation. Broere [7] first monitored the variation in pore water pressure during shield tunnelling in the Heinenoord tunnel and summarized the zigzag variation patterns, in which the pore water pressure increased during tunnelling and decreased after tunnelling stopped. Xiao et al. [8] deduced the formula of excess pore water pressure distribution based on the Mohr-Coulomb yield criterion and concluded that soil friction angle and shield slurry pressure had great impacts on excess pore water pressure responses. Wei et al. [9] used the stress release theory to derive the formula of initial excess pore water pressure of soil adjacent to the tunnel lining. Wang et al. [10] revealed the characteristics of pore water pressure distribution in front of shield tunnelling based on the Mindlin solution and Henkel formula. Xu and Bezuijen [11] considered transient flow in a semiconfined flow and unconfined steady-state flow and proposed two theoretical solutions to describe the variation in excessive pore water pressure in front of the shield in saturated sandy soil. With the rapid development of computer technology, the finite element method has become widely used in research on pore water pressure. Yasuhiko and Hirotaka [12] reproduced the liquefaction process of sand soil based on the discrete element method, taking into account the dynamic change in pore water pressure and found that the effective average stress of sandy soil was inversely proportional to the initial porosity at the steady state. Sahoo and Kumar [13] adopted the finite element limit method to calculate the seepage force generated when groundwater flows toward the tunnel excavation face and the required support pressure. Compared with the dry formation, the support pressure required for tunnelling in the water-rich sand stratum increased remarkably. Li et al. [14] established a three-dimensional fully coupled flow deformation model based on Biot theory and rheological theory.
The studies above had paid little attention to pore water pressure responses in sand stratum during shield tunnelling, which is one of the most important reasons for the collapse of sandy ground. Based on a cross-river highway shield tunnel in China, both the field test and numerical simulation on pore water pressure during shield tunnelling were carried out, and the responses of the pore water pressure in a waterrich fine sand stratum were analyzed. The effect of fine sand stratum grouting reinforcement is evaluated by comparative analysis of the permeability coefficient of the stratum and support pressure of the shield.

\section{Project Overview}

The cross-river tunnel project includes two separate tunnels; the northern tunnel is $1615 \mathrm{~m}$ long, and the southern tunnel is $1423 \mathrm{~m}$ long. Shield tunnelling starts from the launching shaft on the east bank of the river and reaches the receiving shaft on the west bank after crossing the river. The singlelining type tunnel is adopted, with an $11.3 \mathrm{~m}$ outer diameter and $2.0 \mathrm{~m}$ width of the segments (Figure 2). The shield tunnel is mainly located in the stratum of a highly weathered-medium-weathered conglomerate. The overlying soil is mainly fine sand stratum in the flood plain on the west bank of the river, which is brownish yellow, wet to saturated, and slightly dense to medium dense. When the northern tunnel (first line) tunneled into the flood plain, relatively large surface settlement was found $[15,16]$.

Based on laboratory tests and engineering experience, the main engineering properties of the fine sand soil are summarized as follows: The in situ fine sand is slightly medium dense. There is a certain amount of clay particles in the sandy soil, but the cohesive force is very low (approximately $5-10 \mathrm{kPa}$ ). The stability and bearing capacity of soil are mainly maintained by the friction between particles, and the internal friction angle is between 30 and 32. The composition of the soil particles is uniform, and $75.1 \%$ of the particles are less than $5 \mathrm{~mm}$ in diameter. 


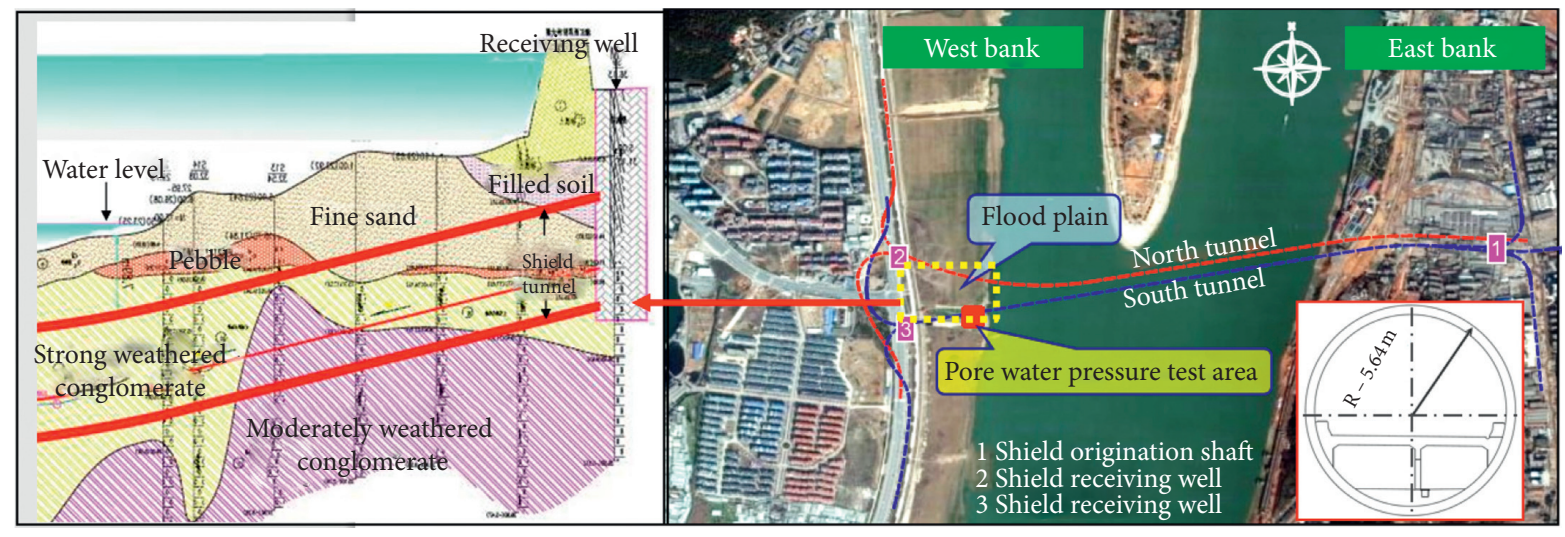

Figure 2: Overview of cross-river tunnel.

\section{Analysis of Pore Water Pressure with Field Test Data}

To investigate the fluctuation and distribution of the pore water pressure in the water-rich sand stratum in front of the shield, a field test experiment of the pore water pressure was carried out before the southern tunnel (second line) had reached the flood plain.

3.1. Field Test Scheme for Pore Water Pressure. The field test area was mainly in the fine sand stratum, with a cover thickness of $7 \mathrm{~m}-8 \mathrm{~m}$ (approximately $0.6 \mathrm{D}$, where $D$ is $11.65 \mathrm{~m}$ and represents the outside diameter of the tunnel). Sections $1-5$ of the pore water pressure test sections were arranged along the longitudinal direction of the tunnel, and the distance between adjacent monitoring sections was $D / 2$. Two test points, M1 and M2, were set at every test section directly above the tunnel. The pore water pressure gauge was embedded at each test point, and the vertical distances from the tunnel vault were $1.0 \mathrm{~m}$ and $3.0 \mathrm{~m}$, respectively. Section 3 was considered as the key test section, where five pore water pressure test points N1 N5 were set on the transverse horizontal axis of the tunnel, and the spacing between adjacent measuring points was $D / 2$, as shown in Figure 3. Due to the limitations of drilling conditions, the test points at Section 4 were not working.

3.2. Distribution of Longitudinal Pore Water Pressure. The test data from Section 2 and Section 3 were selected to analyze the distribution and variation of the pore water pressure in the fine sand stratum when the shield approached, passed, and left the test area (see Figures 4 and 5).

According to the curves above, the impact of shield tunnelling on pore water pressure could be divided into three stages: before the arrival of shield cutterhead, the passage of the shield, and the departure of the shield tail. We take the variation in the pore water pressure in Section 3 as an example.

In the first stage, when the cutterhead of the shield was close to Section 3, the pore water pressure gradually increased as the shield was pushed forward to squeeze both the front and lateral soil masses.

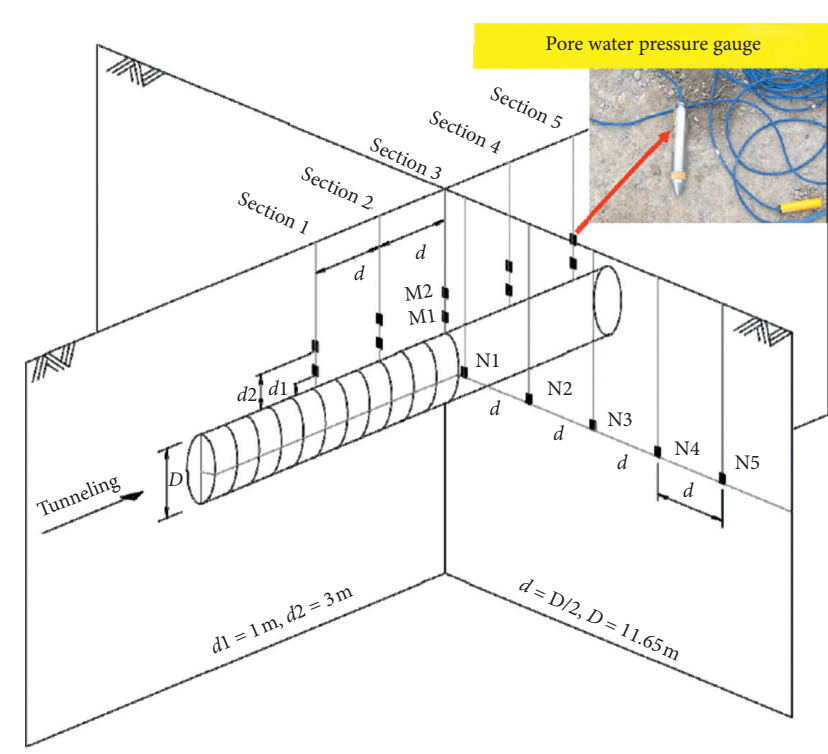

FIGURE 3: Layout of the pore water pressure testing points.

In the second stage, when the cutterhead of the shield reached and passed Section 3, the pore water pressure significantly increased and reached the peak value. The test value at $\mathrm{M} 1$ was $110 \mathrm{kPa}$, and the value at M2 was $84 \mathrm{kPa}$, which was twice the pore water pressure in the first stage. With the shutdown of the shield tunnelling (shield cutters maintenance and replacement), the pore water pressure suddenly dropped to $41 \mathrm{kPa}$, with a decrease rate of approximately 60\%. During the shutdown of the shield tunnelling (d16-d22), grouting was carried out on the outside of the segment behind the tail of the shield; the pore water pressure in Section 3 tended to rise in fluctuation at this time.

In the third stage, grouting from the shield tail was finished, tunnelling was resumed, and the shield tail left Section 3. The pore water pressure at M1 increased to $78 \mathrm{kPa}$. This indicated that when the shield tunnelling resumed after long-term shutdown, it would produce great disturbance to the surrounding fine sand stratum. As the shield tunnelling continued, the pore water pressure slowly dropped, tended to be stable, and after 7-8 $d$ it remained at the level before the shield cutterhead reached Section 3 . 


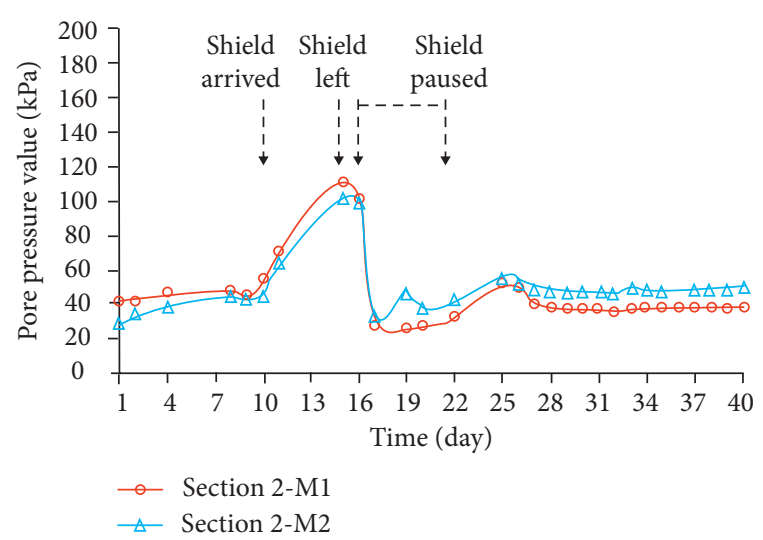

FIgUre 4: Curves of the pore pressure in Section 2.

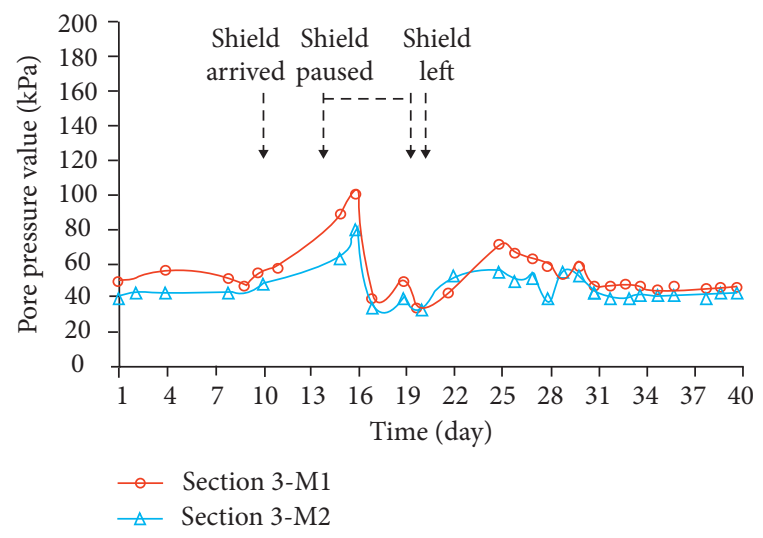

Figure 5: Curves of the pore pressure in Section 3.

In the process of shield tunnelling, excess pore water pressure responses varied specially. According to the difference between the pore water pressure and hydrostatic pressure in Sections 1-5, a distribution diagram of excess pore water pressure at the tunnel vault along the tunnelling direction was drawn, as shown in Figure 6. During the shield tunnelling, the excess pore water pressure showed a decreasing trend along the longitudinal direction of the tunnel. When the shield cutterhead reached Section 1, the excess pore water pressure in Section 1 reached $35 \mathrm{kPa}$, and the excess pore water pressure in Sections 2-5 decreased successively. The excess pore water pressure in Section 5 was not significantly affected and was lower than $5 \mathrm{kPa}$.

The longitudinal pore water pressure responses indicated that the pore water pressure in the surrounding soil increased significantly and reached a peak when the shield approached the test section. After the shield passing through, the pore water pressure gradually dissipated and slowly dropped back to the initial level. The excess pore water pressure at the near field of the shield cutterhead was greater than that at the far field. The disturbance range of the pore water pressure in front of the cutterhead was approximately 2.0 times the excavation diameter (equal to the distance between Sections 1 and 5).

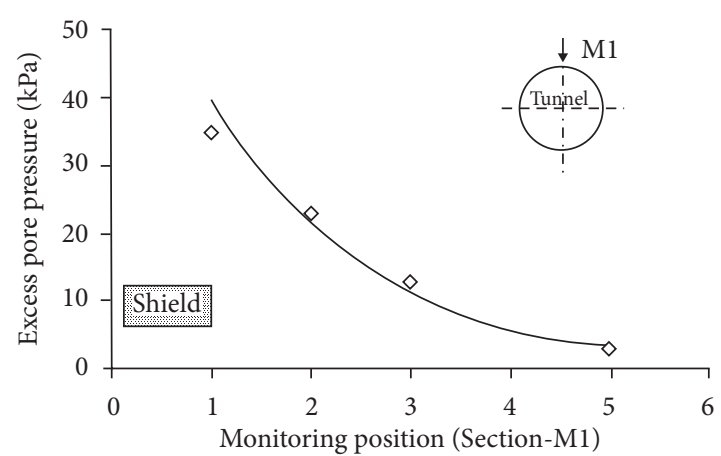

FIgURE 6: Distribution of excess pore water pressure in the longitudinal section.

3.3. Distribution of Transverse Pore Water Pressure. Figure 7 shows the lateral pore water pressure variation in Section 3, which has 5 test points along the transverse direction. Due to the limitations of drilling conditions, the test points N3 and N5 were not worked.

Other than the longitudinal distribution of pore water pressure, the transverse pore water pressure showed a different fluctuation trend. When the shield cutterhead was close to Section 3, the pore pressure at N1 had already reached to a high level and fluctuated within a small range (the average value is $79 \mathrm{kPa}$ ). Due to the shutdown of the shield tunnelling, the pore water pressure at N1 dropped with a decrease rate of approximately $72 \%$. After the shield tail left, the pore pressure fluctuated under the influence of the grouting pressure and then tended to $57 \mathrm{kPa}$; the excess pore water pressure caused by tunnelling could be considered as $24 \mathrm{kPa}$. The pore water pressure at N2 showed the similar variation trend, and the excess pore water pressure here was about $13 \mathrm{kPa}$. Test point $\mathrm{N} 4$ produced excess pressure less than $2 \mathrm{kPa}$ when the cutterhead passed through. Conclusion could be summarized as follows:

(1) The pore pressure increased slowly before the shield cutterhead reached the monitoring section. The disturbance range of the pore water pressure on both sides of the tunnel caused by shield tunnelling was 1.5 times the excavation diameter at most (equal to the distance between N1 and N4).

(2) The fluctuation in the slurry pressure or grouting pressure, long-term abnormal shutdown, and other factors would cause obvious variation in the pore water pressure and lead to great disturbance to the surrounding fine sand stratum.

\section{Numerical Simulation for Excess Pore Water Pressure}

The conventional approach for the analysis of interaction between the seepage field and the stress field during tunnelling is going like this: the seepage analysis conducted first, then the seepage force has been applied to the stress field, and finally the weak form of flow deformation analysis is achieved. This method is simple and easy to implement, but it cannot truly reflect the coupling mechanism between the 


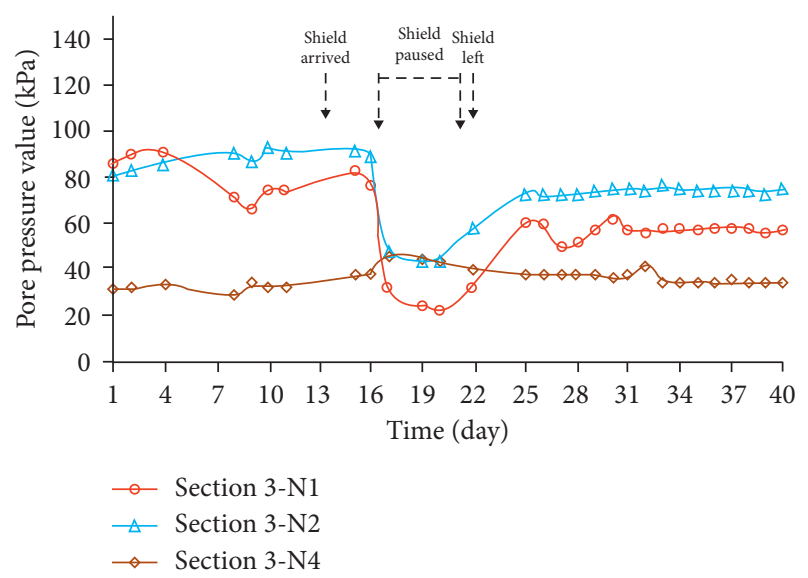

Figure 7: Variation curves of pore pressure for the cross section in Section 3.

seepage field and the stress field. Thus, it is necessary to analyze the fully coupled flow deformation effects on tunnelling disturbances. Fluid-solid coupling theory can be adopted to study the interaction of two-phase media between fluid and solid states. During the actual seepage process, the change in the pore water pressure will alter the effective stress and further change both the permeability coefficient and the porosity of soil skeleton. These changes in turn affect fluid flow and the distribution of the pore water pressure [17]. Based on the stress balance equation, seepage continuity equation, node displacement and pore water pressure shape function, the solution type, initial conditions, and boundary conditions of the pore water pressure were set in ABAQUS, and the coupled calculation of the seepage field and stress field was carried out with the direct coupling method within the framework of Biot consolidation theory.

4.1. A 3D Fluid-Solid Coupling Numerical Model. Generally, a numerical model involves elements such as soil, shield shell, segments, shield tail clearance, and stratum grouting. This paper focused on the disturbance of the pore water pressure near the excavation face caused by shield construction, and the numerical model was appropriately simplified to take into account the slurry penetration zone unit, the segment lining unit, and the support pressure (equal to the slurry pressure for the slurry shield) on the excavation face.

4.1.1. The Establishment of the Finite Element Model. To reduce the influence of the boundary effect, the calculated size of the model in this paper was $120 \mathrm{~m} \times 80 \mathrm{~m} \times 60 \mathrm{~m}$, which was 5 times the tunnel diameter on both sides of the tunnel horizontally and 3.5 times the tunnel diameter below the bottom of the tunnel. The buried depth of the tunnel was $12.0 \mathrm{~m}$ (approximately $1 D$ ), and the water table was measured from the surface. The outer diameter of the shield segment was $11.3 \mathrm{~m}$, the inner diameter was $10.3 \mathrm{~m}$, the ring width was $2 \mathrm{~m}$, and the thickness was $0.5 \mathrm{~m}$. The Mohr-Coulomb elastoplastic constitutive model was selected, and the tunnel segments were C50 reinforced concrete structures with impermeability grade P12, which was set as an elastic material, and the stiffness reduction of the segments was considered. A solid unit (C3D8P) was adopted to simulate the soil mass and segments. The model was divided into 52960 units, as shown in Figure 8.

Referring to the literature results [18], the average penetration thickness of the slurry into the soil in front of the cutterhead was $2.0 \mathrm{~m}$, and the average penetration thickness above and below the cutterhead was $1.4 \mathrm{~m}$. The slurry permeability coefficient in the fine sand stratum was $2.06 \times 10^{-6} \mathrm{~m} / \mathrm{s}$, and that in the strongly weathered conglomerate formation was reduced by an order of magnitude $\left(1.88 \times 10^{-7} \mathrm{~m} / \mathrm{s}\right)$. Considering the shield tunnelling disturbance effect, the elastic modulus of the slurry penetration zone was one-third of the surrounding soil mass.

\subsubsection{Boundary Condition}

(1) Displacement Boundary. Horizontal constraints in the direction of $X$ were applied to the left and right sides of the model; horizontal constraints in the direction of $Z$ were applied to the front and back sides of the model; vertical constraints in the direction of $Y$ were applied to the bottom of the model; the top surface was a free surface.

(2) Seepage Boundary. Both sides and the bottom of the model were impermeable boundaries. The groundwater level was taken from the surface, so the top boundary of the model was set as the permeable boundary with zero pore pressure. The permeability coefficient of the tunnel segments was small. For the inner surface of the segments, the permeability coefficient was equivalent to the nondrainage interface. The excavation face was set as the permeable boundary, and the water head applied on the excavation face was the initial water head.

4.1.3. Model Physical and Mechanical Parameters. The physical and mechanical parameters of each stratum were obtained through detailed survey data and geotechnical experiments, as shown in Table 1. The structural parameters of the tunnel were selected according to relevant specifications.

4.1.4. Simulation of the Shield Tunnelling Process. First, the stress balance analysis was carried out. In the ABAQUS fluid-solid coupling analysis module, parameters such as initial porosity, initial pore pressure, effective stress, and gravity load should be set to balance the pore water pressure and effective stress.

The birth and death function of the unit was adopted to realize the excavation and segment assembly during shield tunnelling. The first step was a one-time excavation of $16.0 \mathrm{~m}$ (8 rings), after which each excavation step was set to $4.0 \mathrm{~m} \mathrm{(2}$ rings). The last step was excavation to the middle of the model. Boundary conditions and tunnelling process simulation were shown in Figure 9. 


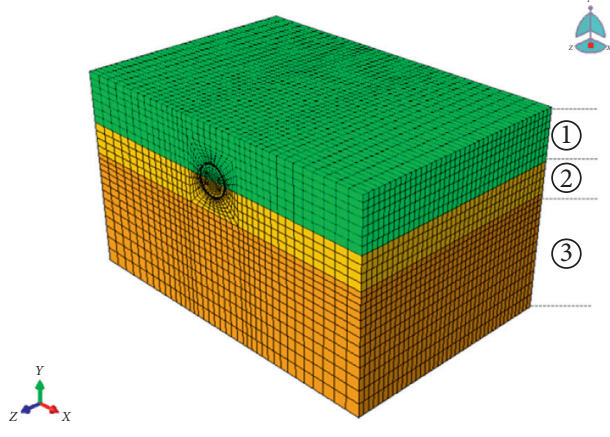

(a)

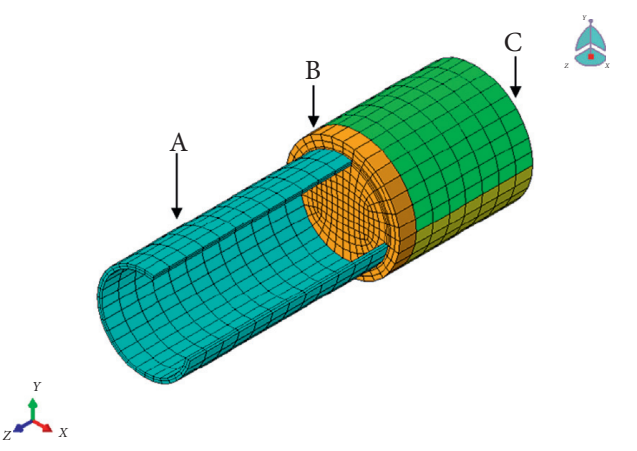

(b)

Figure 8: Three-dimensional coupled fluid-solid numerical model. (a) The meshed numerical model. (b) Schematic diagram of the model components. (1) Fine sand; (2) highly weathered conglomerate; (3) medium-weathered conglomerate. A, lining unit; B, slurry penetration zone (unloading unit); and $\mathrm{C}$, soil element in front of the shield.

Table 1: Parameters of the finite element model.

\begin{tabular}{lccccccc}
\hline Number & $\begin{array}{c}\text { Unit weight } \\
\mathrm{kN} \cdot \mathrm{m}^{-3}\end{array}$ & $\begin{array}{c}\text { Elasticity modulus } \\
E(\mathrm{MPa})\end{array}$ & $\begin{array}{c}\text { Poisson ratio } \\
\mathrm{N}\end{array}$ & $\begin{array}{c}\text { Cohesion } \\
c(\mathrm{kPa})\end{array}$ & $\begin{array}{c}\text { Friction angle } \\
\varphi\left({ }^{\circ}\right)\end{array}$ & $\begin{array}{c}\text { Void ratio } \\
e\end{array}$ & $\begin{array}{c}\text { Permeability coefficient } \\
k(\mathrm{~m} / \mathrm{s})\end{array}$ \\
\hline 1 & 18.9 & 25 & 0.35 & 10 & 30 & 0.69 & $2.06 e-4$ \\
2 & 23.5 & 256 & 0.29 & 185 & 32 & 0.54 & $1.88 e-6$ \\
3 & 24.3 & 2200 & 0.25 & 1200 & 38 & 0.43 & $5.75 e-7$ \\
4 & 25.0 & 34500 & 0.2 & - & - & - & $1.0 e-13$ \\
\hline
\end{tabular}

(1) fine sand; (2) highly weathered conglomerate; (3) medium-weathered conglomerate; (4) concrete segments.

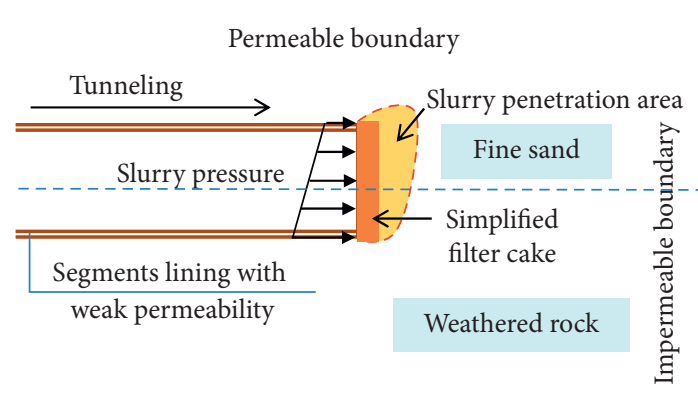

$$
\stackrel{Y}{Y} \quad \text { Impermeable boundary }
$$

FIGURE 9: Boundary condition settings and construction process simulation.

4.2. Pore Water Pressure Simulation. The fluid-solid coupling calculation during shield tunnelling was carried out and compared with the field monitoring data. As shown in Figure 10, the horizontal axis shows the horizontal distance between the longitudinal monitoring section and the shield excavation surface, and the vertical axis shows the excess pore water pressure at the position of the M1 points. In Figure 11, the horizontal axis shows the horizontal distance between the transverse monitoring points and the edge of the shield. The meaning of the vertical axis is the same as that in Figure 10.

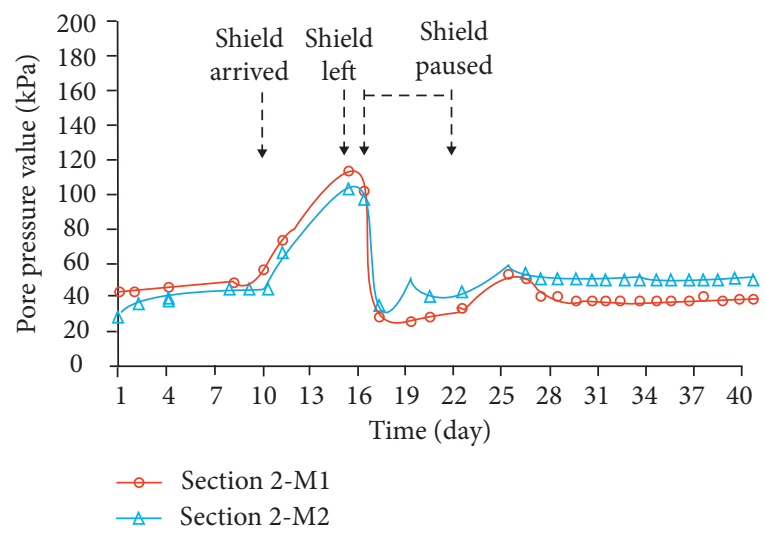

FIgURE 10: The longitudinal curves.

The excess pore water pressure at the near field of the shield cutterhead was generally larger than that at the far field. The impact range of shield tunnelling on the pore water pressure in front of the cutterhead was approximately 2.0 times the excavation diameter, and the impact range on the lateral pore water pressure was approximately 1.5 times the excavation diameter during shield tunnelling.

The pore pressure responses and its distribution obtained by numerical calculation were in good agreement with the field monitoring results, which indicated that the three-dimensional fluid-solid coupling model could be used 


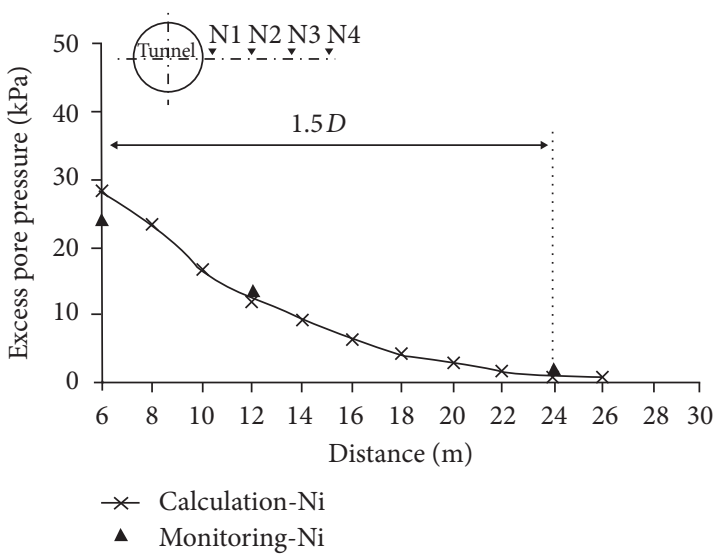

FIgURE 11: The lateral curves.

to analyze the pore pressure responses in the fine sand stratum. The stratum and construction conditions in practical engineering were more complicated, so discrepancy between model simulation and monitoring data can be observed.

\subsection{Impact Factors of Excess Pore Water Pressure}

4.3.1. The Filter Cake Quality. During shield tunnelling, the fine particles in the slurry permeate into the stratum under the action of the difference between the support pressure and the underground water pressure, and gradually form a slightly permeable or impermeable filter cake. When the filter cake was formed on the excavation face and converted partial slurry pressure into soil effective stress, the stability of the excavation face could be achieved during tunnelling [19]. The filter cake quality imposed an important impact on the nonlinear variation in the pore pressure, permeability of the surrounding strata, and the transformation of the effective slurry pressure. Through the coupling calculation, the pore water pressure under conditions of different permeable filter cakes was analyzed. As shown in Figure 12, if the quality and permeability of the filter cake formed on the excavation face were different (Case 1: $2.06 e-6 \mathrm{~m} / \mathrm{s}$, Case 2: $2.06 e-4 \mathrm{~m} / \mathrm{s}$ ), the two-way isolation function of the filter cake would be different, which could be manifested by the distribution of the excess pore water pressure.

Case 1: If the filter cake formed on the excavation face was dense, the permeability was very small. Lower permeability in the filter cake would prevent slurry particles penetrating into the stratum and thus results in a rapid drop in excess pore water pressure within the surrounding areas $(0.5 D)$. For the range of $0.5 D-2.0 D$, the excess pore water pressure decreased slowly and approached zero gradually.

Case 2: If the filter cake quality was poor with high permeability, quantities of slurry under pressure would permeate into the front stratum, leading the pore water pressure around the shield to increase significantly. The excess pore water pressure gradually decreased along the direction of shield tunnelling, with an influence range of $2.0 D$.

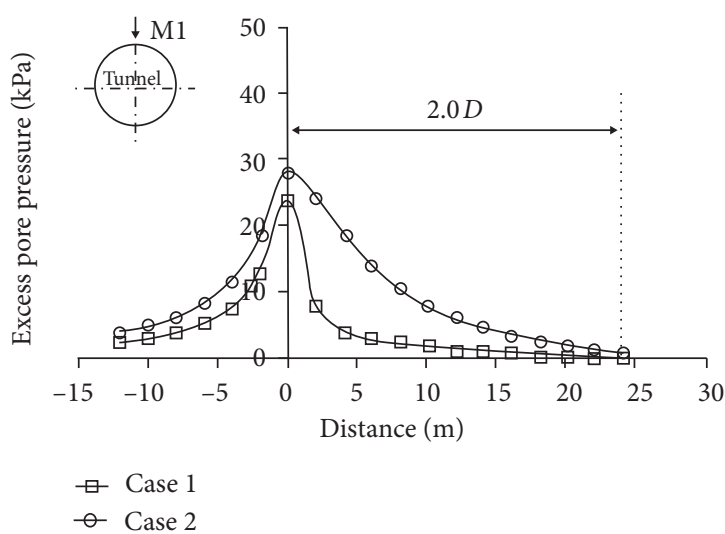

FIgURE 12: Distribution of excess pore water pressure under different permeability conditions.

Compared with the calculation results in Case 1 and Case 2 , the pore water pressure in the fine sand stratum would be significantly disturbed by shield tunnelling in the range of $0.5 \mathrm{D}$ if the dense and stable filter cake was formed on the excavation face (Case 1). The pore water pressure in the fine sand stratum would be significantly disturbed in the range of $2.0 D$, if the high-quality filter cake was not formed on the excavation face (Case 2). The excess pore water pressure value generated in Case 2 was much greater than that in Case 1. It was indicated that, under the condition of poor filter cake quality, the disturbance degree and range of the stress state of the fine sand stratum were significantly larger than those of the high-quality filter cake.

4.3.2. The Support Pressure. If the support pressure was less than Earth pressure in front of the excavation face, the filter cake could not be formed easily, which would lead to the unbalanced force between support pressure and excavation face. If sufficient support pressure was applied, it was still difficult to form a high-quality filter cake due to the mismatch between slurry property and the stratum. A large amount of pressurized slurry would be permeated into the stratum, thus leading to a significant increase in the surrounding pore water pressure, which would also cause great disturbance to the stratum.

Therefore, proper support pressure was one of the most important factors for the formation of high-quality filter cake and the stability of the excavation face. The disturbance to the surrounding stratum induced by support pressures was analyzed, under the condition of high permeability of the filter cake. The support pressure $p$ was distributed in a trapezoidal manner along the vertical direction in front of the excavation face, and its value was equal to the sum of the underground water pressure, soil pressure, and preload at the corresponding location. The support pressure in Case 1 was set as $p$, and that in Case 2 was set as $1.2 p$. The distribution of the excess pore water pressure under different support pressures can be obtained, as shown in Figure 13.

Case 1: when trapezoidal support pressure $p$ was applied on the excavation face, the maximum excess pore 


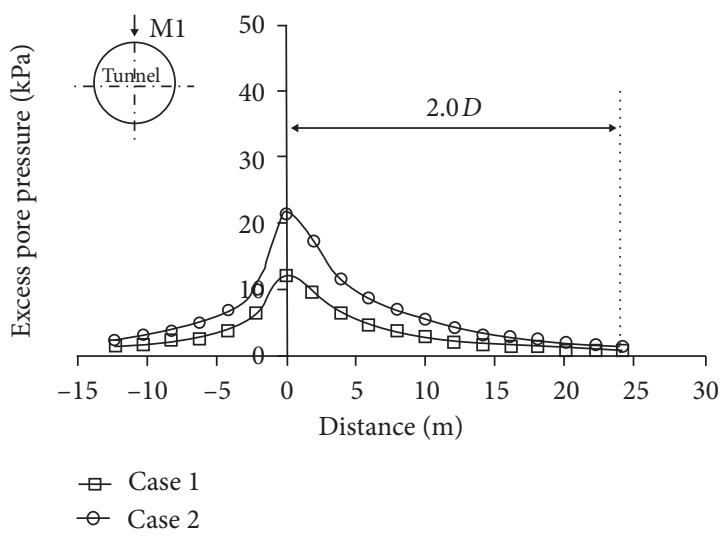

FIGURE 13: Distribution of excess pore water pressure under different support pressures.

pressure during shield tunnelling was $11.9 \mathrm{kPa}$, and the longitudinal influence range of the pore pressure was $20 \mathrm{~m}$ (slightly less than 2.0D).

Case 2: when trapezoidal support pressure $1.2 p$ was applied on the excavation face, the maximum excess pore pressure during shield tunnelling was $22.9 \mathrm{kPa}$, and the longitudinal influence range of the pore pressure was $25 \mathrm{~m}$ (slightly more than 2.0D).

Compared with the calculation results in Case 1 and Case 2 , the curve slope of the pore pressure was basically the same. If the support pressure was set as $1.2 p$, the maximum disturbance factor was 2 times that of $1.0 p$, and the longitudinal disturbance range of the pore pressure in Case 2 was $5 \mathrm{~m}$ larger than that in Case 1 . Once the support pressure exceeded the soil and water pressure on the excavation face $(1.2 p)$, the disturbance degree and range to the stratum would be greater.

\section{Conclusions}

Through field test of pore water pressure and three-dimensional numerical model of fluid-solid coupling, the response of excess pore water pressure caused by large-diameter slurry shield tunnelling in a water-rich fine sand stratum was studied. The following conclusions were obtained:

(1) The tunnelling of a slurry shield in a water-rich fine sand stratum would lead to the formation of an excess pore water pressure zone in the front and sides of the shield. It appeared that the excess pore water pressure at the near field of the shield cutterhead was generally larger than that at the far field. The disturbance range of the pore water pressure of the soil in front of the shield cutterhead was approximately 2 times the excavation diameter and 1.5 times the excavation diameter on both sides of the shield cross section. The fluctuation in the slurry pressure or grouting pressure, long-term abnormal shutdown, and other factors would cause obvious variation in the pore water pressure and lead to great disturbance to the surrounding fine sand stratum.
(2) The pore pressure responses and its distribution obtained by numerical calculation were in good agreement with the field monitoring results. The pore water pressure responses indicated that the pore water pressure in the surrounding soil increased significantly and reached a peak when the shield approached the test section. After the shield passing through, the pore water pressure gradually dissipated and slowly dropped back to the initial level. The tunnelling steps would cause obvious variation in the pore water pressure and lead to great disturbance to the surrounding fine sand stratum. The three-dimensional fluid-solid coupling model could be used to analyze the pore pressure responses in the fine sand stratum. To ensure the safety of the subsequent tunnelling in the fine sand layer, effective treatment should be taken.

(3) Under the condition of poor filter cake quality on the excavation face, the disturbance degree and range of the stress state in the fine sand stratum were significantly greater than that of high-quality filter cake. The disturbance of stratum stress could be reduced noticeably by improving filter cake quality. In the case of high permeability of the filter cake, the larger the value of the support pressure was, the higher the disturbance degree and the larger the disturbance range of the fine sand stratum, once the support pressure exceeded the soil pressure on the excavation face.

\section{Data Availability}

The data used to support the findings of this study are available from the corresponding author upon request.

\section{Conflicts of Interest}

The authors declare that there are no conflicts of interest regarding the publication of this paper.

\section{Acknowledgments}

This work was sponsored by the National Natural Science Foundation of China (no. 51708564), Guangdong Basic and Applied Basic Research Foundation (no. 2020A1515011271), and the Fundamental Research Funds of Sun Yat-sen University (no. 18lgpy31). The authors are grateful to these institutions for their support.

\section{References}

[1] K. Hong, "Typical underwater tunnels in the mainland of China and related tunneling technologies," Engineering, vol. 6, no. 3, pp. 871-879, 2017.

[2] J.-F. Zhu, H. Zhao, Z.-Y. Luo, and H.-X. Liu, "Investigation of the mechanical behavior of soft clay under combined shield construction and ocean waves," Ocean Engineering, vol. 206, p. $107250,2020$.

[3] J. Zhang, T. Feng, F. Zhang, and W. Li, "Experimental study on improvement of seawall filler materials composed of sea 
sand and sea mud," Marine Georesources \& Geotechnology, vol. 38, no. 2, pp. 193-203, 2020.

[4] Z. Wang, W. Yao, Y. Cai, B. Xu, Y. Fu, and G. Wei, "Analysis of ground surface settlement induced by the construction of a large-diameter shallow-buried twin-tunnel in soft ground," Tunnelling and Underground Space Technology, vol. 83, pp. 520-532, 2019.

[5] Y. Fang, Z. Chen, L. Tao, J. Cui, and Q. Yan, "Model tests on longitudinal surface settlement caused by shield tunnelling in sandy soil," Sustainable Cities and Society, vol. 47, p. 101504, 2019.

[6] J.-F. Zhu, R.-Q. Xu, and G.-B. Liu, "Analytical prediction for tunnelling-induced ground movements in sands considering disturbance," Tunnelling and Underground Space Technology, vol. 41, pp. 165-175, 2014.

[7] W. Broere, Influence of Excess Pore Pressures on the Stability of the Tunnel Face, pp. 759-765, Claiming the Underground Space, Amsterdam, Netherlands, 2003.

[8] L. Xiao, Q. H. Zhang, and J. W. Hu, "Analytical solution of excess pore water pressure caused by shield tunnelling," Journal of TongJi University (Natural Science), vol. 39, no. 2, pp. 194-198, 2011.

[9] X. J. Wei, W. J. Chen, and G. Wei, "Research on distribution of initial excess pore water pressure due to shield tunnelling," Rock and Soil Mechanics, vol. 33, no. 7, pp. 2013-2019, 2012.

[10] Z. L. Wang, L. F. Shen, J. B. Xie, and J. Yao, "Analysis of excess pore water pressure induced by shield tunnelling in front of excavation face," Journal of the China Railway Society, vol. 35, no. 5, pp. 90-96, 2013.

[11] T. Xu and A. Bezuijen, "Analytical methods in predicting excess pore water pressure in front of slurry shield in saturated sandy ground," Tunnelling and Underground Space Technology, vol. 73, pp. 203-211, 2018.

[12] O. Yasuhiko and O. Hirotaka, "Coupling pore-water pressure with distinct element method and steady state strengths in numerical triaxial compression tests under undrained conditions," Landslides, vol. 4, no. 4, pp. 357-369, 2007.

[13] J. P. Sahoo and B. Kumar, "Support pressure for stability of circular tunnels driven in granular soil under water table," Computers and Geotechnics, vol. 109, pp. 58-68, 2019.

[14] Z. Li, Z. Luo, C. Xu, and J. Tan, "3D fluid-solid full coupling numerical simulation of soil deformation induced by shield tunnelling," Tunnelling and Underground Space Technology, vol. 90, pp. 174-182, 2019.

[15] J. Zhang, Y. Liang, and T. Feng, "Investigation of the cause of shield-driven tunnel instability in soil with a soft upper layer and hard lower layer," Engineering Failure Analysis, vol. 118, Article ID 104832, 2020.

[16] Y. Liang, X. Chen, J. Yang, J. Zhang, and L. Huang, "Analysis of ground collapse caused by shield tunnelling and the evaluation of the reinforcement effect on a sand stratum," Engineering Failure Analysis, vol. 115, Article ID 104616, 2020.

[17] I.-M. Lee and S.-W. Nam, "The study of seepage forces acting on the tunnel lining and tunnel face in shallow tunnels," Tunnelling and Underground Space Technology, vol. 16, no. 1, pp. 31-40, 2001.

[18] W. Y. Xia, Study on Coupled Solid-Fluid Problem of Shield Tunnel during Construction Period, Doctoral Dissertation, Southeast Jiaotong University, Chengdu, China, 2011.

[19] F. Min, W. Zhu, and X. R. Han, "Filter cake formation for slurry shield tunneling in highly permeable sand," Tunnelling and Underground Space Technology, vol. 38, pp. 423-430, 2013. 